\title{
Western Australian High School Students' Understandings about the Socioscientific Issue of Climate Change
}

\begin{abstract}
Climate change is one of the most significant science issues facing humanity, Yet, teaching students about climate change is challenging; not only is it multidisciplinary, but it is contentious and debated in political, social and media forums. Students need to be equipped with an understanding of climate change science to be able to participate in this discourse. The purpose of this study was to examine Western Australian high school students' understanding of climate change and the greenhouse effect, in order to identify their alternative conceptions about climate change science and provide a baseline for more effective teaching. A questionnaire designed to elicit students' understanding and alternative conceptions was completed by 438 Year 10 students (14-15 years-old). A further 20 students were interviewed. Results showed students know different features of both climate change and the greenhouse effect, however not necessarily all of them and the relationships between. Five categories of alternative conceptions were identified. The categories were (1) the greenhouse effect and the ozone layer; (2) types of greenhouse gases; (3) types of radiation; (4) weather and climate; and (5) air pollution. These findings provide science educators a basis upon which to develop strategies and curriculum resources to improve their students' understanding and decision-making skills about the socioscientific issue, climate change.
\end{abstract}

Contact details

Professor Vaille Dawson

Faculty of Education

The University of Western Australia

M428, 35 Stirling Hwy, Crawley, Western Australia 6009 Australia

Email: Vaille.dawson@uwa.edu.au

Phone +610400221945 


\section{Western Australian High School Students' Understandings about the Socioscientific Issue of Climate Change}

\section{Introduction}

According to the United Nations Millenium Project's global futures research (Glenn, Gordon \& Florescu, 2014, p.15), the issue of "sustainable development and climate change" is one of the most important global challenges facing humanity. Understanding and addressing this global environmental issue will require international collaboration. As future global citizens, school science education needs to equip all young people with the skills and understandings to be scientifically literate.

The socioscientific issue that is the focus of the research reported here is climate change. In this paper, climate change is defined as "a change in the average pattern of weather over a long period of time. Greenhouse gases play an important role in determining climate and causing climate change" (Australian Academy of Science, 2010, p.3). The greenhouse effect is a natural phenomenon where "light from the sun passes through the atmosphere and warms the surface of the Earth. The Earth's surface then releases this heat into the air. Greenhouse gases in the air, such as carbon dioxide, absorb this heat" (Climate Commission, 2014). This radiation is emitted in all directions including towards the Earth's surface. An increase in greenhouse gases increases the temperature of the Earth.

Climate change meets the criteria for a socioscientific issue because the science is emerging and subject to change, it is debated in public media outlets and it is controversial in that members of the public can hold opposing views regarding the science, consequences and causes. Climate change also has ethical, political and social dimensions. Although the consequences and solutions are not clear, climate change will have a global impact that requires international collaboration to understand and address.

In Australia, the recently released State of the Climate 2014 (Bureau of Meteorology and CSIRO, 2014) highlights that in the past 100 years, Australia's climate has increased by 0.9 degrees Celsius with an increased frequency of extreme weather events, increased rainfall and flooding in the north with decreased rainfall in the south. The incidence of extreme fire weather and heat waves has also increased. It is predicted that average temperatures will continue to increase and average rainfall will decrease, although the incidence of heavy 
rainfall will increase. Globally, the mean temperature has increased by 0.85 degrees Celsius and sea level has risen by $225 \mathrm{~mm}$ in the past 140 years and the annual global carbon dioxide concentration is at its highest level in 800,000 years.

Despite these measurable changes in climate, the 2013 fourth annual survey of over 5000 Australian adults found that while $81 \%$ agree that climate change is occurring, less than half $(47 \%)$ agree that climate change is caused largely by humans (Leviston, Price, Malkin, \& McCrea, 2014). These figures have changed little since the first survey in 2010. In addition, climate change was ranked seventh out of eight environmental concerns. Our previous research with 15 year olds ranked climate change sixth out of ten environmental issues (Dawson \& Carson, 2013).

The aim of this study was to determine students' prior knowledge, in particular, their alternative conceptions about climate change and the greenhouse effect, in order to inform the development of curriculum resources and teacher professional development to aid in developing students' scientific literacy about the socioscientific issue of climate change. The curriculum resources are designed not only to address alternative conceptions but to develop students' argumentation and decision-making skills.

\section{Theoretical Framework}

\section{Scientific Literacy}

Internationally, an important goal of formal school science education is to enable all students to develop a sophisticated understanding of the world around them, and to use their understanding of science to make informed, balanced and evidence-based decisions about socioscientific issues that impact their lives (see for example, American Association for the Advancement of Science, 2001; Hodson, 2010; Osborne \& Dillon, 2008). In Australia, significant emphasis has been placed on the importance of scientific literacy in science education (Rennie, Goodrum \& Hackling, 2001; Tytler, 2007). Scientifically literate students tend to be described in a practical way, being able to solve practical problems for health and survival, in a civic way, being able to participate more fully in debate and decision making, and in a cultural way, being motivated to know about science as a human endeavour (Shen, 1975). As Rennie, Goodrum and Hackling (2001) state succinctly:

Scientifically literate persons are interested in and understand the world around them, 
are sceptical and questioning of claims made by others about scientific matters. They participate in the discourses of and about science, identify questions, investigate and draw evidence-based conclusion, and make informed decisions about the environment and their own health and well-being (p.494).

Overall, Australian students perform well in international studies of scientific literacy. For example, the Programme for International Student Assessment (PISA) coordinated by the Organisation for Economic Cooperation and Development (OECD) found that, in the 2006 results where scientific literacy was a focus, Australian 15-year-old students were outperformed in the domain of scientific literacy by only three countries (Finland, Hong Kong-China and Canada) out of the 57 participating countries (Thomson \& De Bortoli, 2008). Three aspects of scientific literacy were measured: identifying scientific issues, explaining phenomena scientifically, and using scientific evidence. In 2009 and 2012, Australian students achieved similar average scores to 2006 in science but were outperformed by more countries/economies (OECD, 2013).

In PISA 2006, students' attitudes to science and environmental issues were also measured. Of concern is that despite their outstanding results in scientific literacy, Australian students scored lower than the OECD average in relation to how concerned they were about the environment (ranked 46/57 countries) and how optimistic they were that environmental problems can be solved (ranked 47/57 countries). Because it is essential that young people are able to deal effectively with environmental issues, research is needed to determine how best to develop students' scientific literacy about issues such as climate change (Robottom \& Simonneaux, 2012).

\section{Socioscientific Issues}

The term socioscientific issues was used in the science education literature as early as 1986 (Fleming, 1986). Socioscientific issues are scientific topics that are "based on scientific concepts or problems, are controversial in nature, are discussed in public outlets and are frequently subject to political and social influences" (Sadler \& Zeidler, 2005, p.113). Individuals are frequently faced with choices about socioscientific issues such as whether or not to eat genetically modified foods, vaccinate children or undergo genetic testing. Furthermore, as a society there is a need to make decisions about climate change mitigation, energy resources (e.g., wind farms), population control and water supply and quality. 
Recently, there have been calls for education about socioscientific issues to be incorporated into Australian schools. For example, the Melbourne Declaration on Educational Goals for Young Australians (Barr et. al, 2008) stated that "complex environmental, social, and economic pressures such as climate change that extend beyond national borders pose unprecedented challenges ... to meet these challenges, Australians must be able to engage with scientific concepts and principles, and approach problem-solving in new and creative ways" (p. 5). In response to the Melbourne Declaration, the Australian Curriculum Assessment and reporting Authority (ACARA) developed the Australian curriculum in science in which the rationale states that the "curriculum supports students to develop the scientific knowledge, understandings and skills to make informed decisions about local, national and global issues" (ACARA, 2014, p. 1). The curriculum includes a strand called Science as a human endeavour, which requires students to consider the nature and influence of science on people. For example, "using science knowledge to evaluate whether they should accepts claims, explanations or predictions" (ACARA, 2014).

Science education researchers have argued that socioscientific issues can and ought to be used as contexts for learning science (Hodson, 2013; Sadler, 2004; Sadler \& Dawson, 2012). They suggest that contemporary social issues with conceptual ties to science can serve as a basis for improving students' understanding of science and nature of science, generate interest and motivation for learning science and support development of critical thinking skills and argumentation practices. Teaching about socioscientific issues can lead to deep and meaningful learning compared with more traditional content driven approaches because students are more engaged and see personal relevance in the science they do in their classrooms. However, it is worth noting that there is debate and dissent about how to approach the teaching of socioscientific issues in science classrooms (Bryce \& Day, 2014; Fensham, 2014; Hodson, 2013).

Despite the importance of climate change as a global problem requiring a co-operative political and economic response, young people's understanding of climate change science and the greenhouse effect is weak (e.g. Hansen, 2010). Internationally, a number of studies have examined young people's understanding of climate change and the greenhouse effect (e.g., Andersson \& Wallin, 2000; Boyes \& Stanisstreet, 1993; Koulaidis \& Christidou, 1999; Shepardson, Niyogi, Choi \& Charusombah, 2009). These studies have revealed that alternative conceptions about climate change and the greenhouse effect are held by students of all ages (primary, secondary and tertiary). The most frequently cited alternative 
conceptions relate to confusion between the ozone layer and greenhouse effect. Students perceive that damage to the ozone layer (by carbon dioxide) causes global warming (Rye, Rubba \& Weisenmayer, 1997). There is also confusion regarding infrared and ultraviolet radiation, and weather and climate. Air pollution is also perceived to cause global warming. In Australia, Boon (2009) examined Year 8 and 10 Queensland students' understanding of the greenhouse effect, ozone depletion and climate change and compared them to Boyes and Stanisstreet's (1993) study. She found little difference in students' conceptions despite increased exposure in the media and school.

Hansen (2010) used a simple seven item questionnaire to survey Year 10 (15 year old) Norwegian students in $1989(n=348), 1993(n=354)$ and $2005(n=440)$ about their understanding of the greenhouse effect and climate change. The questionnaire comprised statements such as "the greenhouse effect protects us against radiation from the sun" which students ticked if they considered a statement to be correct. He found over the period 19892005 that although there was some improvement in students' understandings of the causes and effects of the greenhouse effect there was an increase in confusion between the greenhouse effect and the ozone layer.

Our recent research (Dawson \& Carson, 2013) conducted in 2011/12 used some of the same items as Hanson (2010) with Western Australian students and found that almost half (48\%) of a sample of 438 students agreed with the statement that "the greenhouse effect is caused mainly by ozone". A total of $90 \%$ agreed with the statement that "the greenhouse effect is caused mainly (emphasis added) by carbon dioxide". Furthermore, almost half (47\%) of the students were not aware that the greenhouse effect is necessary for life. These initial findings led to the study reported here which is a detailed examination of students' understanding and alternative conceptions about the greenhouse effect and climate change.

\section{Significance of Study}

This study is significant for four reasons. First, the topic of climate change is arguably, the most important socioscientific issue that teachers could choose to address, given its political and contentious nature, emerging science and impact on all citizens (unlike surrogacy, for example, which is unlikely to impact on many students). Second, most peer reviewed studies about climate change understanding use a single data source only (often questionnaire). There has been criticism about using questionnaires alone to determine students' understandings of climate change and the greenhouse effect because of concerns that questionnaires are 
insufficient for students to state all that they know (Jakobsson, Mäkitalo, \& Säljö, 2009). This study uses two data sources, a written questionnaire and oral interviews to address the research questions. Third, the study is conducted in Australia, a country that has been impacted by severe weather events (flooding and bush fires) and unprecedented high temperatures in the past three years. We did not think it was possible to generalise the findings of past international studies to a recent Australian context. There have been two previous studies conducted in Australia (Boon, 2009; Boyes, Skamp \& Stanisstreet, 2009). Boon (2009) conducted her study in four regional Queensland schools with a sample that included younger students and focussed on understanding of the greenhouse effect while Boyes, Skamp and Stanisstreet (2009) reported on students' beliefs about the usefulness of various actions to reduce climate change. Finally, the outcomes of this study are to inform conceptual change curriculum resource development and teacher professional development, for subsequent implementation and evaluation.

\section{Aim of Study}

Specifically, the aim of this study was to examine Western Australian Year 10 students' understanding of climate change and the greenhouse effect to provide a baseline for the development of quality resources, implementation of curriculum, and use of effective teaching strategies. The research questions that are addressed in this study were:

1. What do students understand about climate change science and the greenhouse effect?

2. What alternative conceptions do students have about climate change science and the greenhouse effect?

\section{Method}

Sample

Using a qualitative research method (Merriam, 2009), questionnaire data was obtained from a sample of 438 Year 10 (14-15 year old) students from six schools in Perth, Western Australia. The sample comprised 249 girls (57\%) and 189 (43\%) boys. The schools were selected through purposive sampling for diversity in school type (Independent, Catholic and government), socioeconomic status (high, medium and low), location (metropolitan and 
regional) and science curriculum (climate change included or not included). Year 10 students were chosen because it is the last year of formal schooling when science is compulsory. The diversity in school type enabled us to sample a wide range of students. A further 20 Year 10 students (12 boys and 8 girls) from two more schools (School A and School B) were interviewed to probe their understanding of the greenhouse effect and climate change. The 10 students from School A had recently been taught about climate change and the greenhouse effect. The ten students from School B had not been taught about climate change and the greenhouse effect in science. The interviewed students were selected by their teachers to comprise a mix of high, low and medium science ability.

\section{Data Sources}

A written questionnaire was completed by students to determine their understanding of climate change and the greenhouse effect. Students responded to questions about their understanding and the challenges, controversies, and consequences of climate change. The open-ended questions were almost identical to those used by Klosterman and Sadler (2010) to determine 15 year old high school students' understandings of the causes and controversy related to global warming. The only difference was that the term, climate change, was used in place of global warming. This change reflected the change in language used in the media and research literature about climate change. The questionnaire was completed during the students' science classes. Students were provided with as much time as needed and were assured that they could leave individual questions blank.

The semi-structured interviews (Merriam, 2009) were conducted with 20 students in pairs and trios at their school during their science classes in a separate laboratory preparation area. The students were interviewed in friendship groups to reduce anxiety and to limit the amount of time that students were absent from class. Initially, the interviewer introduced herself, explained the purpose of the study and stated that she was interested in their understanding of climate change and the greenhouse effect. After introductory remarks, each student was asked if they had been taught about climate change and the greenhouse effect. Students were then asked an open question about their understanding of climate change. When each student ceased speaking, follow up questions were asked (e.g., is there anything else you would like to add? can you tell me more?, anything else?). The second student was then asked the open ended question. After each student had responded to the question about climate change, the 
interviewer asked about the greenhouse effect. The interviews which varied in length from five to 20 minutes were audiotaped and fully transcribed.

\section{Data Analysis}

The complete response from each student questionnaire $(n=438)$ was entered into the data base, SPSS. Analysis of the responses occurred through a two-step process. In the first step, the aim was to determine whether students' could correctly define climate change and the greenhouse effect. The questions, what is the greenhouse effect?, and what is climate change?, were analysed separately. Informed by Klosterman and Sadler's (2010) approach and the definitions (from the Introduction), the first step involved an apriori analysis to identify the elements of a correct definition. In this first step, a sample of 40 responses were examined and categories which ranged from most accurate to least accurate were identified. The responses were independently coded by two researchers. Where there was uncertainty or disagreement, discussion ensued and agreement was reached. The remaining sample was coded by one researcher.

In the second step, all questionnaire responses were re-analysed using inductive analysis. In this second step, students' responses were categorised and coded using a grounded theory approach (Corbin \& Strauss, 2008). Categories that corresponded to different alternative conceptions were identified and described. Initially, the two questions were analysed separately. However, with the exception of, "climate change is happening quickly", examples of each type of alternative conception were found in both questions. Thus, the results are presented concurrently.

The interview transcripts were also analysed with a two-step process using the same categories as those developed with the questionnaire responses. The two data sources enabled triangulation.

\section{Results}

\section{Questionnaire Results}

The students' responses to the question, what is the greenhouse effect? are summarised in Table 1. Correct or partially correct responses were grouped according to three categories similar to that used by Klosterman and Sadler (2010). The remaining responses were 
classified as 'underdeveloped', 'incorrect' or 'no response'. Only one in three students (156, $36 \%$ ) were able to provide a correct or partially correct response.

Insert Table 1 about here

In defining the greenhouse effect, 88 (20\%) students correctly described the relationship between greenhouse gases and increasing temperature or warming. This category was considered to be closest to a correct response as defined earlier by the Climate Commission (2104). Examples of student responses included:

The greenhouse is a natural process that maintains the earth's average surface temperature at $15^{\circ}$. Greenhouse gases in the troposphere absorb long wave radiation that is reflected by the earth's surface, and retain it as heat. This keeps heat in the atmosphere, making life on Earth sustainable. (342)

The greenhouse effect is when greenhouse gases (gases that retain heat in the atmosphere) are released into the atmosphere causing the earth to heat up. This is similar to the effect in a greenhouse which is where the term greenhouse effect comes from. This is caused by gases such as $\mathrm{CO}_{2}$ and $\mathrm{CO}$. (439)

A further $54(12 \%)$ students mentioned warming, heat or increasing temperature in their response, indicating they knew that the greenhouse effect had something to do with warming the Earth (whether it be natural or enhanced). Examples included:

The greenhouse effect is the natural and essential part of the atmosphere that traps heat, ensuring a comfortable temperature on earth. It is essential for human life. (408)

It is a natural process that maintains the earth's average temperature of $15^{\circ}$. The atmosphere allows short wave radiation to pass through the earth and then radiates long wave radiation back and trap it, creating a 'blanket' around the earth keeping it the ideal temperature for life on earth. Without the greenhouse effect it would be impossible for life on earth to survive. (337)

A small number of students $(n=14)$ described greenhouse gases in their response but did not mention their involvement in the warming of the Earth. Examples included:

Gases that cause an effect on the Earth's atmosphere. (65)

$\mathrm{CO}_{2}$, water vapour, methane, blanket for Earth. (371) 
Almost half (48\%) of the students' responses were underdeveloped (9\%) or incorrect (39\%). Examples of underdeveloped responses included "The Earth getting warmer" (150) and "When a blanket is put around the earth and heats it up" (165). Incorrect answers included "you put plants in a greenhouse" (173) and "the natural gas from every living thing" (190)

Table 2 summarises the students' responses to the question, what is climate change? Correct or partially correct responses were grouped according to four categories similar to that used by Klosterman and Sadler (2010). The remaining responses were classified as 'underdeveloped', 'incorrect' or 'no response'. Only one in three students $(153,35 \%)$ were able to provide a correct or partially correct response.

Insert table 2 about here

The correct response was based on that provided by the Australian Academy of Science (2010) and includes the features of a changing climate, influence of greenhouse gases or greenhouse effect and warming or increasing temperature. A total of 90 (21\%) students described these features. For example:

Climate change is the increase in global temperatures and therefore change in climate on Earth due to the enhanced greenhouse effect which is caused by human activities such as fossil fuel burning and deforestation which in turn creates greenhouse gases as by-products. When there is more greenhouse gases more heat energy is trapped in the atmosphere. (333)

I think climate change is something to do with the greenhouse effect and the temperature rising and something to do with ice melting. (421)

A small proportion $(32,7 \%)$ of students provided a response indicating climate change was a change in climate or weather patterns over a long period of time. This group frequently demonstrated an understanding that climate change has occurred in the past and did not focus on the current period of global warming.

Climate change is any long term variation in the atmosphere due to precipitation patterns and can be due to either natural causes and (sic) human activities. (131)

A long term significant change in the weather patterns of the Earth and an area. (178) 
A small number $(31,7 \%)$ of students mentioned warming, heating or increasing temperature as well as an effect of this temperature increase, indicating an understanding of the relationship between global warming and climate change.

Climate change is the change in temperature which the earth is experiencing. It is causing ice caps to melt, sea levels to rise and many species are becoming extinct. (402)

Climate change is the gradual increase in the Earth's average temperatures. This in turn would affect many species and ecosystems, also changing the landscape of the Earth e.g. melting glaciers, ice caps etc. (130)

A total of $66(15 \%)$ students mentioned warming or increasing temperature only.

Climate change is the environment gradually changing as the earth gets warmer, the cold countries climate have increased and the warmer countries climates increases even more. (415)

The rising temperature of the earth. (129)

Almost $43 \%$ of the students provided a response that was underdeveloped (15\%) or incorrect (28\%). Examples of underdeveloped answers included, "When the climate changes massively because of humans or unnatural things." (2) and "Climate change is a change in climate."(29) An incorrect response was "it's when $\mathrm{CO}_{2}$ is sprayed into the ozone layer which kills the oxygen which cause the heat to get through the atmosphere" (279).

\section{Alternative Conceptions About the Greenhouse Effect and Climate Change}

In response to the question, what is the greenhouse effect?, nearly half $(198,45 \%)$ of the students expressed at least one type of alternative conception in their answer. There were 286 examples of alternative conceptions expressed by 198 students. Of the 198 students, 122 mentioned one alternative conception only, 64 students mentioned two and 12 students mentioned three different alternative conceptions. In response to the question, what is climate change?, a quarter $(111,25 \%)$ of the students expressed at least one alternative conception in their answer. There were 140 examples of alternative conceptions expressed by 111 students. Of the 111 students, more than three quarters (86) expressed only one type of alternative conception, with 22 students mentioning two alternative conceptions, two students 
mentioning three and one student providing four alternative conceptions. Overall, 245 (56\%) of the 438 students expressed at least one alternative conception.

The types and frequency of alternative conceptions from both questions are summarised in Table 3. The alternative conceptions are listed in order of decreasing frequency. A total of 10 types of alternative conceptions were identified. The alternative conceptions can be collapsed into five main groups: confusion about the greenhouse effect and the ozone layer; nature of greenhouse gases; types of radiation; weather and climate; and air pollution.

Insert table 3 about here

Two of the most commonly cited types of alternative conceptions related to confusion about the nature of the greenhouse effect and the ozone layer. There were two discrete types of responses in this group. The first was that the greenhouse effect and/or greenhouse gases are destroying or weakening the ozone layer thus allowing more heat or radiation to enter the atmosphere or reach the Earth. This type of alternative conception occurred in 82 responses and was the second most frequently mentioned alternative conception. Examples included:

Climate change is a result of greenhouse gases destroying the ozone layer causing drastic changes in global temperatures. (224)

The greenhouse effect is the ozone layer breaking and letting in UV rays which cause our environment to heat up. After the ozone layer closes, the UV rays are stuck in the atmosphere, heating this up. (114)

The second type of response related to general confusion and combining features of both phenomena. A total of 64 responses indicated confusion between the two. For example:

Climate change is when the ozone layer traps more solar radiation than necessary because of a build-up of gases in the atmosphere. The trapped radiation gradually increases the average temperature in different parts of the world which can melt ice caps, making hotter places even hotter. (14)

The greenhouse effect is a natural process by the ozone layer around our world. The gases in the ozone layer include nitrogen, oxygen and carbon dioxide. These gases are like gases in a greenhouse, they insulate and protect the world with solar heat radiating from the sun. (105) 
The most common alternative conception described by students about greenhouse gases was that $\mathrm{CO}_{2}$ alone caused the enhanced greenhouse effect, with 85 students illustrating this in their response. For example,

Climate change is when there is an increase of carbon dioxide in the atmosphere causing the enhanced greenhouse effect, leading to the climate changing. (363)

Greenhouse effect is the large amount of $\mathrm{CO}_{2}$ in our atmosphere and the heating up of the $\mathrm{CO}_{2}$. Humans have caused large $\mathrm{CO}_{2}$ emission. (226)

A smaller proportion of responses $(n=24)$ referred to the greenhouse effect as a process of "trapping" of (greenhouse) gases. It is possible that students were confusing the idea of heat being 'trapped' by greenhouse gases and the greenhouse gases themselves.

[The greenhouse effect is] the trapping of gases. Usually when the sun emits heat it passes through the Earth's atmosphere, bounces off the ground, where some heat remains in the atmosphere while the rest goes back into space. The greenhouse effect traps gas and keeps excess heat in the atmosphere. (90)

The greenhouse effect is when $\mathrm{CO}_{2}$ created from burning fossil fuels and when these fossil fuels are trapped in the atmosphere and this causes Earth to start heating up. It's like a greenhouse and doesn't let the $\mathrm{CO}_{2}$ get out of the atmosphere. (374)

Thirteen of the responses mentioned how greenhouse gases "thickened" the atmosphere almost like a physical barrier and that this barrier allowed heat to enter but not to leave. For example:

Climate change is the increase in gases that causes the atmosphere to thicken and lets the heat that goes into the earth have less chance of escaping. (63)

The greenhouse effect is when fossil fuels are burnt and release carbon dioxide resulting in the barrier around the earth to thicken which lets heat in but not out. (261)

Eleven responses indicated that students thought that greenhouse gases were harmful using the words "poisonous" and "toxic" in their answer. For example:

Climate change is a difference in temperatures caused by an increased greenhouse effect because of pollution from burning fossil fuels and releasing poisonous gases into the atmosphere. (470) 
The entrapment of toxic gases in our atmosphere. (317)

A proportion of responses $(n=46)$ expressed confusion regarding ultra-violet light and infrared light and solar radiation versus terrestrial radiation. More than half of these students mentioned the ozone layer in their responses indicating they may have known that the ozone layer protects the earth from ultraviolet radiation.

Climate change is when we humans have polluted the ozone so much that our atmosphere is not reflecting as much UV rays as normal and is absorbing more heat. The heat is then trapped by the carbon dioxide, methane and other pollution gases which have absorbed the UV rays. Thus causing the Earth to warm up and get hotter. (268)

The greenhouse effect is a natural process which warms the earth. Natural gases such as methane, carbon dioxide and water vapour make a blanket of gases in the troposphere. That blanket retains some of the UV rays that are reflected off the earth. (355)

A small number of responses $(n=26)$ demonstrated confusion between climate and weather. This included changes in the weather such as a change in the seasons. For example:

Climate change is the change in weather, temperature from the previous day. (409)

[The greenhouse effect is] when the weather is getting colder in winter and hotter in summer. (211)

Also included in this group were 22 students who referred to climate change as a process that happened quickly.

I think that climate change is when the temperature of the climate changes rapidly. (211)

Climate change is where the temperature changes over a short time causing environmental problems. (322)

The role of pollution as a cause of climate change and/or the greenhouse effect was described in 60 responses. For example: 
[The greenhouse effect is] when heat coming into the earth cannot escape because we have thickened the atmosphere due to pollution. (252)

[Climate change is] increased pollution adding to our greenhouse effect causing the climate on earth to increase in heat. (241)

It is possible that some student's use of the term, 'pollution' may be referring to carbon dioxide produced from the burning of fossil fuels rather than particulate pollution.

\section{Student Interviews}

In this section, pseudonyms are used throughout. The ten students from School A had recently been taught about climate change science and the greenhouse effect in an Earth Science topic. Although the students from School B had not formally studied climate change in science, eight of the ten students stated that they had learnt about climate change previously through books, television, geography, primary school or at a science centre. Using the same categories as the questionnaire to define climate change and the greenhouse these students were better able to define the terms. All ten students from School A were able to provide a definition that was categorised as correct. For example, in defining the greenhouse effect, Lily stated, "basically what happens is when the sun's rays hit the Earth, it reflects back and the greenhouse gases reflect that back and doesn't allow the heat to escape. The greenhouse gases are water vapour, carbon dioxide, which is very little, and other gases that do not allow the heat to escape". All ten students from School A mentioned water vapour and other gases in addition to carbon dioxide. All of the students from school B mentioned gases or carbon dioxide playing a role in increasing temperature.

The students from School A described climate change as a phenomena occurring over a long period of time with periodic ice ages. They also described volcanoes, forest fires and fuel emissions as causes of climate change. More than half of the 20 students defined climate change as an increase in temperature over a long period of time.

Although the interviewed students were able to provide more accurate definitions than the students who completed questionnaires, nearly half of the students from both schools still expressed alternative conceptions related to the greenhouse effect and ozone layer. Marcus from school A stated "the ozone layer protects the earth from harmful UV rays from the sun and the greenhouse gases attack the ozone layer and eats away at it." Lucy and Gerry from School B gave a detailed (incorrect) account of the greenhouse effect and climate change. 
Interviewer: My first question is, what is the greenhouse effect? Give as much detail as you can.

Lucy: From my understanding, from what I read about it in the book, is it to do with pollution? And how all the gases that are bad go up into the ozone and like destroy the ozone or something.

Gerry: Same with Lucy, that it is air pollution. So things like carbon dioxide and monoxide and stuff going up into the ozone layer and letting in more UV rays to melt and interfere with our climates. Because the Sun would evaporate more clouds and so usually wet areas would get more sunlight and more frozen areas like Antarctica and the North Pole get warmer and more water is going up and it is affecting the hotter areas like Australia.

Interviewer: So what is climate change?

Lucy: Because there is no ozone layer to...I think it softens the UV rays as they come through. So if it comes through the holes in the ozone layer it is getting a direct hit on the Earth rather than being distilled from the ozone layer.

Gerry: It is more of a direct hit from the Sun because it burns holes through the ozone layer. The pollution is taking out holes in the ozone layer. So instead of having an insulation like a house...the ozone layer is designed to be an insulator like a house. So you destroy the insulation and then everything just gets hotter or colder. If it is cold then it is cold and if it is hot it is hot and there is no balance point so no one wins in that.

The alternative conceptions expressed by the interviewed students related primarily to confusion about the greenhouse effect and the ozone layer, types of radiation, and the role of air pollution in causing climate change. Overall, the findings from the interview data support the questionnaire findings that nearly half of the Year 10 students held alternative conceptions.

\section{Discussion}

Many science education researchers have argued that school science should develop students' scientific literacy. An important aspect of scientific literacy is the ability to use one's understanding of science to make informed evidence-based decisions about socioscientific issues. In our previous research with other science concepts there were several decades of 
accumulated research about students' alternative conceptions and ways of addressing them (Treagust \& Duit, 2008). We focussed this study on climate change because it is, arguably, the most important scientific issue facing humanity. Solving or ameliorating the impact of climate change will require global effort and co-operation. When we searched for curriculum resources about climate change, there were few resources and much of the information was factual (e.g., textbooks, government climate change fact sheets). There were few activities that were engaging and student centred and suitable for young adolescents. As a result, we believed it was important to find out what students knew about the topic before developing curriculum resources and teacher professional development. Thus, the aim of this research was to determine Western Australian Year 10 students' understanding of the greenhouse effect and climate change.

We had anticipated that Australian students would exhibit a sound understanding of these topics given their prominence in science curriculum documents, school text books and the media. Climate change and the greenhouse effect are mentioned explicitly in many international science curriculum documents. For example, the Next Generation Science Standards in the US explicitly mention "global climate change" as a disciplinary core idea in high school (National Research Council, 2013, p.196). In the National curriculum in England, "the production of carbon dioxide by human activity and impact on climate" (p.9) is a content topic under Earth and atmosphere in Key Stage 3 (Department for Education, 2013). In Australia, where this study is located, climate change and the greenhouse effect are mentioned explicitly under the science understanding strand of Earth and space sciences (ACARA, 2014).

In this study, only one in three students was able to provide a correct or partially correct written definition of the greenhouse effect and climate change. In addition, more than half of the students $(56 \%)$ mentioned at least one of 10 types of alternative conceptions in their response. The types of alternative conceptions can be categorised into five main content areas: (1) the greenhouse effect and the ozone layer; (2) types of greenhouse gases; (3) types of radiation; (4) weather and climate; and (5) air pollution. Students confused the main gases, location and the function of the greenhouse effect and the ozone layer. Students considered that carbon dioxide was the only greenhouse gas and did not consider the role of methane, nitrous oxide, hydrofluorocarbons and water vapour. Students did not differentiate between solar radiation, infrared and ultraviolet radiation. Students used the terms, 'weather' and 'climate' interchangeably, not seeming to realise that weather is a short term local event 
while climate is a long term pattern of weather. Some students stated (incorrectly) that air pollution (particulate matter which includes heavy metals, dust and sulphur dioxide) causes climate change.

The presence of alternative conceptions present challenges for science educators because students' prior knowledge will influence their learning (Ausubel, Novak \& Hanesian, 1968). If young people are to participate fully in society and grapple with socioscientific issues they need to have sufficient knowledge about the underlying scientific concepts. Students' alternative conceptions about complex scientific concepts such as the greenhouse effect and climate change are difficult to address. The alternative conceptions are often strongly held and may be reinforced by the media and science teaching. A poor understanding is likely to impact on young people's subsequent decision-making and actions. The findings are a cause for concern given the global significance of climate change as a socioscientific issue.

It is beyond the scope of this study to speculate on where the alternative conceptions arise. Most of the students interviewed indicated that they had been taught about the topics in school science, geography, primary school or books. They had also watched movies and read about climate change in the media. It is possible that science teaching has contributed to students' alternative conceptions. An understanding of the greenhouse effect and climate change requires an understanding of science concepts such as the carbon cycle, electromagnetic spectrum, heat energy, structure of the atmosphere, gases, and the difference between weather and climate (Jarrett, Ferry \& Takacs, 2012). Simplistic representations of the greenhouse effect in school text books may also contribute. For example, many of the diagrams in text books show light rays entering the atmosphere, reflecting from the surface of the earth and being reflected back from a certain height. This may contribute to students' perceptions that there is a discrete layer of gas, similar to the ozone layer.

There is evidence that targeted teaching interventions can be effective in improving students' understanding of climate change science. Klosterman and Sadler (2010) implemented a three week intervention based on the socioscientific issue of global warming and found a statistically significant improvement in Year 10 students' understandings of the underlying science content. Varma and Linn (2012) used a web-based inquiry module of $5 \mathrm{x}$ one hour lessons with Year 6 students to teach them about the greenhouse effect and global warming. They also found a significant improvement in students' understandings of the causes and consequences of global warming. McNeill and Vaughn (2012) reported similar improvements 
in Year 11/12 students' understandings of climate change with an 11 lesson intervention focussed on environmental action. All of these interventions introduced climate change as a socioscientific issue. In these cases, the researchers worked intensively with the teachers providing them with resources and strategies.

Based on the findings of these studies and the research presented here, there is a need for a combination of carefully designed teacher professional development and the development of curriculum resources to assist teachers to teach about socioscientific issues such as climate change (Ekborg, Ottander, Silfver \& Simon, 2012). Teachers need to understand relevant scientific concepts and also be aware of the types of alternative conceptions students may hold. They need to be familiar with teaching strategies to address alternative conceptions (e.g., conceptual change approaches, Treagust \& Duit, 2008).

Informed by the findings of this research, we have developed a curriculum resource for students in Year 7 to 10 comprising four modules specifically designed to improve students' understandings and decision-making about climate change issues. The modules are inquirybased and include activities that use analogies, predict-observe-explain, hands-on student investigations and argumentation about authentic climate change scenarios. Up-to-date accurate and accessible information is provided about electromagnetic radiation, the greenhouse effect and climate change, and sources of greenhouse gases (Dawson \& Carson, 2014).

The curriculum resource is available to teachers after attending a professional development workshop. The main components of the workshop are: an introduction to socioscientific issues (what they are, why they are relevant, teaching strategies), decision-making models (risk-benefit, pros and cons, multiple perspectives), argumentation; climate change science; and students' alternative conceptions. Teachers are then able to trial the modules with their students. It is hoped that these initiatives will contribute towards a better understanding of the socioscientific issue of climate change and improved scientific literacy.

\section{Conclusion}

A sample of 438 Western Australian Year 10 students exhibited a mixed understanding of the greenhouse effect and climate change with about one in three students able to provide a correct or partially correct definition of the greenhouse effect and climate change. More than half of the students expressed one or more of 10 alternative conceptions. The types of 
alternative conceptions demonstrate widespread confusion about the greenhouse effect and the ozone layer; the nature of greenhouse gases; types of radiation; differences between weather and climate; and air pollution. An understanding of the types of alternative conceptions which students hold allows for the implementation of inquiry based teaching strategies, the development of appropriate curriculum resources and informs teacher professional development.

\section{Acknowledgement}

This research was supported under Australian Research Council's Discovery Projects funding scheme (project number DP130103035).

\section{References}

American Association for the Advancement of Science. (2001). Designs for science literacy. Washington, D.C: Author.

Andersson, B., \& Wallin, A. (2000). Students' understanding of the greenhouse effect, the societal consequences of reducing $\mathrm{CO}_{2}$ emissions and the problem of ozone layer depletion. Journal of Research in Science Teaching, 37(10), 1096-1111.

Australian Academy of Science. (2010). The science of climate change: Questions and answers. Canberra: Author.

Australian Curriculum Assessment and Reporting Authority [ACARA]. (2014). The Australian curriculum: Science. Retrieved 25 August, 2014 from http://www.australiancurriculum.edu.au

Ausubel, D., Novak, J., \& Hanesian, H. (1968). Educational psychology: A cognitive view. New York: Holt, Rinehart and Winston.

Barr, A., Gillard, J., Firth, V., Scrymgour, M., Welford, R., Lomax-Smith, J., \& Constable, E. (2008). Melbourne Declaration on Educational Goals for Young Australians. Victoria, Australia: Ministerial Council on Education, Employment, Training and Youth Affairs [MCEETYA].

Boon, H. (2009). Climate change? When? Where? The Australian Educational Researcher, $36(3), 43-65$. 
Boyes, E., Skamp, K., \& Stanisstreet, M. (2009). Australian secondary students' views about global warming: Beliefs about actions, and willingness to act. Research in Science Education, 39(3), 661-680.

Boyes, E. \& Stanisstreet, M. (1993). The 'Greenhouse Effect': children's perceptions of causes, consequences and cures. International Journal of Science Education, 15(5), 531552 .

Bryce, T., \& Day, S. (2014). Scepticism and doubt in science and science education: the complexity of global warming as a socio-scientific issue. Cultural Studies of Science Education, 9, 599-632.

Bureau of Meteorology, \& Commonwealth Scientific and Industrial Research Organisation [CSIRO]. (2014). State of the climate: 2014. Retrieved from http://www.bom.gov.au/state-of-the-climate/documents/state-of-the-climate-2014_lowres.pdf?ref=button

Climate Commission. (2014). Causes: Greenhouse effect. Retrieved from http://climatecommission.gov.au/causes/greenhouse-effect/

Corbin, J., \& Strauss, A. (Eds.) (2008). Basics of qualitative research: techniques and procedures for developing grounded theory. Thousand Oaks, CA: Sage

Dawson, V. \& Carson, K. (2014). Climate change and the greenhouse effect. Perth: The University of Western Australia. Retrieved from http://spice.wa.edu.au/resources/gse

Dawson, V, \& Carson, K (2013). Australian Secondary School Students' Understanding of Climate Change. Teaching Science, 59(3), 9-14.

Ekborg, M., Ottander, C., Silfver, E., \& Simon, S. (2013). Teachers' experience of working with socio-scientific issues: A large scale and in depth study. Research in Science Education, 43, 599-617.

Fensham, P. (2014). Scepticism and trust: two counterpoint essentials in science education for complex socio-scientific issues, Cultural Studies of Science Education, 9, 649-661.

Fleming, R. (1986). Adolescent reasoning in socio-scientific issues, part I: Social cognition. Journal of Research in Science Teaching, 23(8), 677-687. 
Glenn, J. C., Gordon, T. J., \& Florescu, E. (2014). 2013-2014 State of the future. Washington, D.C: The Millennium Project.

Hansen, P. J. K. (2010). Knowledge about the greenhouse effect and the effects of the ozone layer among Norwegian pupils finishing compulsory education in 1989, 1993 and 2005 What now? International Journal of Science Education, 32(3), 397-419.

Hodson, D. (2010). Science education as a call to action. Canadian Journal of Science, Mathematics and Technology Education, 10(3), 197-206.

Hodson, D. (2013). Don't be nervous, don't be flustered, don't be scared. Be prepared. Canadian Journal of Science, Mathematics and Technology Education, 13(4), 313-331.

Jakobsson, A., Mäkitalo, Å., \& Säljö, R. (2009). Conceptions of knowledge in research on students' understanding of the greenhouse effect: Methodological positions and their consequences for representations of knowing. Science Education, 93(6), 978-995.

Jarrett, L., Ferry, B., \& Takacs, G. (2012). Development and validation of a concept inventory for introductory-level climate change science. International Journal of Innovation in Science and Mathematics Education, 20(2), 25-41.

Klosterman, M., \& Sadler, T. (2010). Multi-level assessment of scientific content knowledge gains associated with socioscientific issues-based instruction. International Journal of Science Education, 32(8), 1017-1043.

Koulaidis, V., \& Christidou, V. (1999). Models of students' thinking concerning the greenhouse effect and teaching implications. Science Education, 83(5), 559-576.

Leviston, Z., Price, J., Malkin, S., \& McCrea, R. (2014). Fourth annual survey of Australian attitudes to climate change: Interim report. Perth, Australia: CSIRO.

McNeill, K., \& Vaughn, M. (2012). Urban high school students' critical science agency: Conceptual understandings and environmental actions around climate change. Research in Science Education, 42(2), 373-399.

Merriam, S.B. (2009). Qualitative research: A guide to design and implementation (Rev. \& expanded ed.). San Francisco: Jossey-Bass. 
National Research Council (2013), A framework for K-12 science education: Practices, crosscutting concepts, and core ideas. Washington, DC: The National Academies Press.

Organisation for Economic Co-operation and Development [OECD]. (2013). Education at a Glance 2013: OECD indicators. Paris, France: Author.

Osborne, J., \& Dillon, J. (2008). Science education in Europe: Critical reflections. London: The Nuffield Foundation.

Rennie, L.J., Goodrum, D., \& Hackling, M. (2001). Science teaching and learning in Australian schools: Results of a national study. Research in Science Education, 31(4), 455-498.

Robottom, I., \& Simonneaux, L. (2012). Editorial: Socio-scientific issues and education for sustainability in contemporary education. Research in Science Education, 42(1), 1-4.

Rye, J. A., Rubba, P. A., \& Wiesenmayer, R. L. (1997). An investigation of middle school students' alternative conceptions of global warming. International Journal of Science Education, 19(5), 527-551.

Sadler, T. D. (2004). Informal reasoning regarding socioscientific issues: A critical review of research. Journal of Research in Science Teaching, 41(5), 513-536.

Sadler, TD, \& Dawson, VM (2012). Socioscientific issues in science education: Contexts for the promotion of key learning outcomes. In BJ Fraser, K Tobin, \& C McRobbie (eds). The Second International handbook of science education (pp. 799-809). Dordrecht, The Netherlands: Springer.

Sadler, T. D, \& Zeidler, D. L. (2005). Patterns of informal reasoning in the context of socioscientific decision making. Journal of Research in Science Teaching, 42(1), 112138.

Shen, B. S. (1975). Science literacy and the public understanding of science. Communication of scientific information, 44-52.

Shepardson, D. P., Niyogi, D., Choi, S., \& Charusombat, U. (2009). Seventh grade students' conceptions of global warming and climate change. Environmental Education Research, 15(5), 549-570. 
Thomson, S., \& De Bortoli, L. (2008). Exploring scientific literacy: How Australia measures up. The PISA 2006 survey of students' scientific, reading and mathematical literacy skills. Camberwell, Victoria: ACER Press.

Treagust, D.F., \& Duit, R. (2008). Conceptual change: A discussion of theoretical, methodological, and practical challenges for science education. Cultural Studies in Science Education, 3(2), 297-328.

Tytler, R. (2007). Re-imagining science education: Engaging students in science for Australia's future. Camberwell, Victoria: Australian Council for Educational Research Press.

Varma, K., \& Linn, M. (2012). Using interactive technology to support students' understanding of the greenhouse effect and global warming. Journal of Science Education and Technology, 21(4), 453-464. 
Table 1: Response to question "What is the greenhouse effect?"

Nature of response

Number (percentage)

of students $(\mathrm{N}=438)$

Involves greenhouse gases that cause an increase in temperature $88(20)$

(Correct)

Related to temperature/warming (Partially correct)

$54(12)$

Involves greenhouse gases only (Partially correct)

Underdeveloped response

$41(9)$

Incorrect response

$169(39)$

No response

$72(17)$ 
Table 2: Response to question "What is climate change?"

\begin{tabular}{lc}
\hline Nature of response & $\begin{array}{l}\text { Number (percentage) } \\
\text { of students } \\
\text { (N=438) }\end{array}$ \\
\hline A change in climate related to the greenhouse effect (Correct) & $90(21)$ \\
A change in climate/weather patterns over time & $32(7)$ \\
(Partially correct) & $31(7)$ \\
Related to an increase in temperature and consequence given & $66(15)$ \\
(Partially correct) & $64(15)$ \\
Related to an increase in temperature (Partially correct) & $122(28)$ \\
Underdeveloped response & $33(7)$ \\
Incorrect response & \\
No response & \\
\hline
\end{tabular}


Table 3: Alternative conceptions displayed by students

\begin{tabular}{|c|c|c|c|}
\hline Alternative Conceptions & $\begin{array}{l}\text { Number of } \\
\text { responses to the } \\
\text { question, What is } \\
\text { the Greenhouse } \\
\text { Effect? }\end{array}$ & $\begin{array}{l}\text { Number of } \\
\text { responses to the } \\
\text { question, What } \\
\text { is Climate } \\
\text { Change? }\end{array}$ & Total \\
\hline $\mathrm{CO}_{2}$ is the only greenhouse gas & 62 & 23 & 85 \\
\hline Greenhouse gases destroy the ozone layer & 56 & 26 & 82 \\
\hline $\begin{array}{l}\text { Ozone layer is confused with the greenhouse } \\
\text { effect }\end{array}$ & 54 & 10 & 64 \\
\hline Pollution causes the greenhouse effect & 37 & 23 & 60 \\
\hline $\begin{array}{l}\text { Ultraviolet radiation is confused with infrared } \\
\text { radiation }\end{array}$ & 39 & 7 & 46 \\
\hline $\begin{array}{l}\text { Greenhouse gases are trapped by the } \\
\text { atmosphere }\end{array}$ & 19 & 5 & 24 \\
\hline Climate change is happening quickly & 0 & 22 & 22 \\
\hline Climate and weather are confused & 2 & 17 & 19 \\
\hline Greenhouse gases thicken the atmosphere & 8 & 5 & 13 \\
\hline Greenhouse gases are harmful & 9 & 2 & 11 \\
\hline
\end{tabular}

